\title{
Interseções na arte: a criação artística
}

\author{
PAULO BERNARDINO
}

\section{Resumo}

Vivemos numa sociedade que se constitui essencialmente através de uma pele tecnológica composta por imagens. Com a tecnologia sempre presente na história da arte, essencialmente através de imagens, veremos em que medida a tecnologia digital interfere no processo artístico - procurarei refletir em que medida a tecnologia digital tem interferido nos processos artísticos contemporâneos. Na Arte Contemporânea o resultado advindo da utilização da tecnologia e o desejo pela interatividade impulsionanos a perceber o desenvolvimento da idéia de partilha na produção, que se abre como inerente à atitude do ato criativo, e na concretização da obra.

Palavras-chave:

Imagem, tecnologia, criação 


\title{
Intersections in art the artistic creation
}

\author{
PAULO BERNARDINO
}

\section{Abstract}

We live in a society that is constituted mainly by a technological 'skin' of images. The technology has been everpresent throughout the history of art, mainly by pictures; thus I will try to reflect the extent to which digital technology has interfered with the contemporary artistic processes. In Contemporary Art the emerging result of the use of technology and the desire for interactivity take us to understand the development of the idea of 'sharing' as inherent in the creative act and in the the achievement of the work. 
Ao ver as imagens como um elemento que acompanharam desde sempre o desenvolvimento da humanidade, foi-se desenvolvendo em mim, já na pele de artista, uma necessidade de penetrar as diferentes épocas da sua produção para melhor situar o presente constituído pelo passado das imagens e a partir de aí conjeturar o seu futuro.

Ao relacionar tecnologias, técnicas e suportes, encontramos formas de qualificar/ organizar as imagens. Se alinharmos as técnicas segundo um determinado critério logo nos apercebemos e podemos caracterizar as imagens, que refletem as resoluções estéticas que foram organizando crenças e pensamentos que acabaram por reger as épocas que lhes deram origem. Desde logo, com as imagens mais remotas da história do homem, nos começamos a aperceber que estas se foram cruzando com questões de natureza mágica de caráter religioso.

Aos poucos e poucos a função da imagem foi se convertendo na representação do mundo aparente, proporcionando e enquadrando a figuração dentro de ideais estéticos, procurando uma narratividade que a colocou ao serviço da pedagogia, segundo uma orientação educativa dominante, acabando por lhe dar poderes políticos e religiosos remetendo-a para uma condição orientadora de cultos.

De acordo com o seu valor simbólico, tornam-se dependentes dos locais de apresentação e pela operacionalidade dos desenvolvimentos técnicos dos mesmos, adaptando-se aos espíritos das épocas, a imagem foi sofrendo adaptações na sua execução prática começando a revelar uma necessidade inerente de transformar o espaço da representação em espaço de transcrição - que mais do que aludir pretende simular o real de forma persuasiva.

As divergências doutrinais inerentes às abordagens advindas de Roma versus Constantinopla - pela sua vertente orientadora de culto, vemos a imagem penetrar questões absoluta- 
mente determinantes para a sua formação enquanto processo de expansão - acabaram por desenvolver, basicamente, duas formas de olhar/pensar a imagem, orientando o sentido de perceber como é que a saga da imagem se foi afirmando nas sociedades/civilizações mais antigas e como é que ao serviço das religiões a imagem se foi transformando em lição litúrgica, que acabou por atirá-la para uma condição de conflito entre iconoclastas e iconófilos.

O Norte de Itália, pela importância que, particularmente, vai ocupar no desenvolvimento de uma nova abordagem da consciência humana - tendo como lema o Homem - vemos florescer uma nova era onde o termo Renascer dá o mote para o Renascimento, onde se adota, fundado no humanismo, todo um culto do individualismo.

A credibilidade e coerência na apresentação, por um lado, assente no conhecimento matemático-descritivo do espaço tridimensional na representação bidimensional através da geometria, proporcionando ver o local da representação como uma janela (metafórica), por outro, através do desenvolvimento da pintura a óleo, fez com que as imagens sofressem imediatamente uma transformação técnica e estética que superou uma das grandes barreiras da representação até então. Proporcionou-se a procura da objetividade na representação em todos os sentidos, pela capacidade desenvolvida no tratamento da forma que a técnica da pintura a óleo veio facilitar, onde a imagem passa a ocupar, espelhar mimetizando, o visível, libertando o homem da deformação das imagens "imaginadas" que desvirtuam, transformando, a realidade ${ }^{1}$.

Pelo fato de se passar a ter conhecimento da geometria descritiva do espaço, verifica-se um avanço em termos de percepção que permite uma manipulação "real" do espaço de representação. Atitude que por um lado vai influenciar a própria postura do indivíduo criador quanto à sua posição social e, por outro, consequentemente influenciar todo o tratamento dado a luz (claro) e à sombra (escuro) no espaço da obra. O conhecimento desta regra que organiza a obra passa a ser um bem precioso para o domínio da imagem, não apenas pelo fato da geometria necessitar de aprendizagem especifica, mas pela consciência que a própria sociedade começa a encarar e a diferenciar as produções das imagens em função do seu autor.

Pela capacidade que demostra o individuo-artista, onde a sua mais valia passa a revelar-se na atitude (individuo que se encontra numa encruzilhada) - sendo que por um lado tem o passado e por outro o presente - a confrontação da tradi- 
ção e da inovação, a sua relação com as formas impostas e as livremente escolhidas, fez com que estes indivíduos-artistas passassem a ser vistos como seres intelectuais, e como tal eles próprios passaram a ser conscientes do seu valor ${ }^{2}$. O que de certa forma fez com que tenhamos visto aparecer o séc. XV como enunciador de uma nova abordagem à imagem. Procurando-se uma "beleza ideal", que compreenda o Homem, um compromisso com o real, não do ponto de vista da imitação, mas do complemento. Onde o suporte interfere na condição da imagem enquanto veículo difusor dos conteúdos, pois ao transformar-se de paredes em quadros acaba por proporcionar objetos, favorecendo à imagem uma condição de fisicalidade "transportável".

Esta transformação foi altamente incrementada pelo impulso dado à imagem com o aparecimento da prensa de caracteres móveis de Gutenberg (1394-1468), que não só permitiu uma maior divulgação da imagem ${ }^{3}$ (inclusive produziam-se imagens de composições que mais tarde iam dar origem a pinturas), como a colocou ao serviço das ciências.

Porém no que diz respeito sobretudo ao séc. XVI, a Europa é um barril de pólvora, onde se confrontam posições reformistas e contra-reformistas e suas derivantes posições. Peculiarmente todos os países católicos que ficaram posteriormente debaixo de um absolutismo régio. Proporcionando uma comunhão entre clero e nobreza que imediatamente começam a combater a produção cultural independente - advinda essencialmente do Maneirismo - através de ordens estabelecidas com o objetivo de censurar a produção e ao mesmo tempo tentar submeter a criação ao poder instituído - seu único promotor e consumidor. Porém, como nas várias fases de aprendizagem na vida, as limitações não são obrigatoriamente condições que nos levam a abandonar os nossos pressupostos, e como tal na Arte, os artistas, debaixo de adversidades, acabaram por reorganizar numa sintaxe nova, dinâmica e dramática, artificiosa e tecnicista, com grande sentido cênico, todo um espaço propício para a elevação dos sentimentos e das emoções - é o que nos apresenta o Barroco e o Rococó.

Contudo, com o século XVIII, o Século das Luzes, do Iluminismo, vemos despontar toda uma atitude voltada para o princípio depositado na Razão, Liberdade e Progresso, e a produção artística começa a ser questionada ${ }^{4}$ quanto à sua forma e processo, abrindo e procurando formatar aquilo que hoje conhecemos no mundo atual. Se as revoluções Liberais parcialmente puseram fim ao regime Absolutista, a revolução 
Francesa (1789) procurou instituir o direito à autodeterminação dos povos, aristocracia versus povo, ou colocado em linguagem de representação, tradição versus inovação. Por um lado, numa perspectiva mais convencional, o Neoclassicismo, procurando retratar a verdade altruísta, vendo o passado clássico como um exemplo a seguir, e por outro, numa perspectiva mais inovadora, o Romantismo, mais interessado no tratamento das emoções e da natureza, contribuíram para que ambos os estilos, cada um à sua maneira apelando para a dicotomia intelectual derivada de uma posição que facultava e estruturava a sociedade, sobrevivessem em simultâneo.

Porém e indubitavelmente que foi o Romantismo que mais impacto teve no desenvolvimento da arte e consequentemente na construção do discurso da imagem. Pela sua ausência de padrões pré-estabelecidos, comparativamente com os Neoclássicos, os artistas do Românticos podiam olhar o mundo de forma mais audaz, o que fez com que usassem qualquer experiência, real ou imaginária, desde que intensa, e em seu nome acabaram por adorar a emoção pela emoção5. Onde a imagem começa então a evidenciar na sua constituição uma transformação profunda, pois começa a deixar de ser um espaço de representação a que se assistia, que era teatralizado, colocando o público num local tangível, para passar a ser fictícia, para concorrer imagem/ natureza e artista/observador no plano do provável.

Através do crescimento demográfico a que se assiste por toda a Europa do séc. XIX, decorrente da Revolução Industrial, assistimos a uma reformulação da sociedade acabando tal situação por interferir nos modelos, assim como, nos meios de utilizar e produzir imagens. Partindo do legado da imprensa (como já acima mencionado, tecnologia facilitadora de produção e consequente circulação de imagens - através de uma maior distribuição), começa a fazer-se sentir necessidade de uma tecnologia capaz de produzir e difundir imagens ao ritmo da sociedade que se expandia - quer em velocidade quer em quantidade. Começa a operar-se uma transformação radical em todo o mundo, afetando todos os bens de consumo, enquanto objetos, assim como o próprio objeto artístico. Consequência eminente denota-se com o aparecimento das primeiras imagens conseguidas através de processos químicos, mais concretamente com o Daguerreótipo, que acabariam por constituir e dar origem à fotografia preto-e-branco. Numa primeira fase alerta-se e faz-se aparecer uma nova forma de produzir imagens fora da vontade e do saber da mão do artista, distribuindo o conhecimento técnico e a ilusão de democratização da capacidade de produzir imagens. 
Apesar da proeza iniciada pela fotografia preto-e-branco, a grande aventura da imagem técnica só começa a enunciar-se de modo indiscutível com a passagem da fotografia preto-e-branco para a fotografia colorida. As imagens que a fotografia dava ao mundo tornaram-se, e eram vistas, como uma mais valia; sem a intervenção de um intérprete, de um código, de um tratamento alicerçado na tradição, a sua função era colocada como provedora de verdade visual.

Temos então que pela presença da máquina/aparelho a imagem vai ganhar uma evidência do ponto de vista da sua interseção com a realidade, manipulando a nossa crença na sua autenticidade, fazendo com que adquira um valor simbólico operado pela verdade objetiva inerente à qualidade física da situação existente entre fotógrafo e fotografado (SONTAG, 1986). Logo a máquina de impressão ea máquina fotográfica, fazem uma parelha avassaladora no campo da representação. $\mathrm{O}$ compromisso da imagem realista produzido pelo aparelho fotográfico e consequente verdade objetiva, convertem a imagem numa evidência do real, remetendo a produção manual da pintura para a subjetividade, o que mais do que uma diminuição de funções, fez com que esta se torna-se vinculadora de uma procura interior, alargando objetivamente, o seu espectro para lá da tradução da realidade observável. Dava-se desta forma uma transmutação da realidade do espaço da pintura, da representação, da imagem. Ou seja, da arte de uma forma geral.

Podemos portanto afirmar que o que caracteriza o séc. XIX, do ponto de vista da sua transformação enquanto processo de transcrição visual (imagens), foi por um lado, a fotografia, por outro, a ruptura da forma de produzir/criar utilizada no passado, onde o processo de olhar a pintura se volta para si próprio, deixando de lado as preocupações da tradução do visível - mimetismo - e começando uma nova aventura para a imagem e para o pensamento que é de fato a abstração.

Consequentemente, já não está em causa a objetividade que é então condicionada por esta nova tecnologia uma vez que não deixa margens para dúvidas, pois a realidade passa a ser mediada por um meio exterior à produção manual, logo fora da interpretação subjetiva do seu executor. Implementando uma nova visão do espaço, pela ação deste novo suporte, passa a existir uma nova liberdade na criação da imagem para os artistas plásticos. Ficando cada vez mais sujeito o espaço da ilusão a uma nova realidade (onde o objetivo não é representar); da confrontação entre o objeto e a realidade, acaba por se formar novas consciências, expandindo-se e provocando novos espaços de ocupação para o desenvolvimento da arte. 
Na continuidade do plano do progresso, vemos aparecerem novos suportes com o desenvolvimento da tecnologia e do aparelho mecânico. Passa-se para o aparelho electrônico, que transforma mais uma vez a abordagem às imagens, proporcionando novos espaços para o seu desenvolvimento. Indo interferir no processo técnico vai por sua vez obrigar a recolocar, mais uma vez no discurso da imagem, a questão do local expositivo como elemento inerente à própria obra. Pelos meados do séc. XX, assistimos, agora de forma determinante, essencialmente pela mão da tecnologia a grandes alterações nos processos, nos meios e na própria imagem. Na qualidade de meio, vemos aparecer uma tremenda abordagem à informação, quer do ponto de vista da sua preparação quer do ponto de vista da sua difusão, ou seja o desenvolvimento dos meios de comunicação de massas.

Onde vamos perceber que mais do que tudo é no meio que se encontra a grande transformação, e do ponto de vista da criatividade, o aforismo "o meio é a mensagem" (MCLUHAN, 1964), vai introduzir na mente dos artistas uma mudança radical. Já não é o objeto em si que ocupa o centro, mas a preocupação da utilização de um meio, que em si, seja e enumere características que remetam para um tipo de instrumento com propriedades novas para o mundo das artes. Temo então como condição o vídeo (captura e reprodução) - que enquanto meio veio precisamente a tornar-se, em termos tecnológicos e económicos, acessível ao publico. E os artista começam a perceber neste meio uma capacidade de expressão libertadora - através da imagem como sendo em si uma expressão que, conjuntamente com o uso do texto e da voz, remete para uma presença quase irreconhecível, fugindo a uma compreensão/identificação rápida quer da narrativa quer da representação. Devido à sua característica intimista (grava e reproduz a cena em tempo real), a câmara de vídeo, favorece uma relação pessoal com a imagem (plano da identidade) como processo reflexivo da sua condição humana. Pela natureza da sua forma de apresentação (projeção), o espaço físico passa a ser um elemento enunciador de uma nova abordagem à forma artística, a instalação, que obriga a imagem a não ser apenas o alvo da criatividade, mas a própria relação, espaço/tempo/dimensão, a ter uma influência preponderante no comportamento da obra e do observador.

$\mathrm{O}$ séc. XX, essencialmente nos seus meados, através da tecnologias que lhe deram forma, primeiro pela ação do vídeo e depois pelo legado digital, como veremos mais abaixo, alteram-se tecnicamente os processos e a imagem passa a in- 
tegrar o tempo real e o movimento em direto como fatores decisivos na sua constituição. Pela facilidade tecnológica, o nível de intervenção na imagem passa a ser bastante alto logo no momento da sua captura, proporcionando uma desarticulação, em direto, complementando uma sintonia com as experiências estéticas de outras formas de expressão que procuravam mais do que a dialética imagem vs observador, uma abordagem que se afirma pela interatividade. Com a introdução do computador - ferramenta tecnológica que se impõe no cotidiano -, a imagem sofre uma alteração fundamental na sua história. Através da sua facilidade manipulativa vai fazer com que, perdendo o referente ${ }^{6}$, se converta num sistema auto-suficiente que embora não esteja preocupado na tradução da realidade, vai interferir com ela, quer do ponto de vista dos seus valores quer da constituição de novas realidades. As transformações operadas técnica e tecnologicamente pelo advento digital tiveram um impacto real no modo de ver. Com o aparecimento do suporte digital tudo se transforma irremediavelmente. Afere-se a perda da evidência, afetandose a condição de verdade que a imagem ainda transportava e interfere-se na própria construção da realidade. Enquanto suporte, o digital, comprometido com a imaterialidade que lhe é fundadora, permite uma circulação de dados, que integra de forma simbiótica, dando origem a produtos que já não são apenas imagens mas comprometimentos entre som, imagem, tempo e, fundamentalmente, ação, convertendo a imagem numa interface que torna intencional a procura da interatividade. Portanto, ao interferir-se com a forma de operar e produzir, consequentemente interfere-se com o resultado.

Pelo fato de se (con)fundir o verdadeiro e o falso e afastou-se a noção de original. A facilidade reprodutiva, pelo fato de não alterar o original, acentuou a noção de imaterialidade provocando uma catarse na autenticidade, colocando, inclusive e por arrastamento, a materialidade fora da sua arena. Já Walter Benjamin no início do séc. XX, em 1936, havia notado que a reprodutibilidade mecânica iria interferir com a aura da obra de arte, mas a autenticidade não era beliscada, que como prova de autoria estava garantida porque associada ao objeto físico e ao local. Com o aparecimento da internet - a grande metáfora contemporânea da ausência do local - é tudo posto em questão. Onde o computador que é uma ferramenta tecnológica que insere tecnicamente a constituição, alteração e divulgação da imagem, se assume como a máquina capaz de resolver todos os problemas. A manipulação tecnicamente é pos- 
sibilitada até ao elemento mínimo, o pixel, proporcionando um jogo de recombinação infinito dentro dos elementos constitutivos na composição da imagem. Pelo fato, atirando a objetividade para segundo plano criando consequentemente um plano para o desenvolvimento da subjetividade, proporcionando uma realidade afastada da realidade, onde aquilo que se constitui como referente é a imagem, ou seja, são as imagens que constituem a realidade e é através dela que se orientam as imagens. Desenvolvendo assim um circuito fechado - virtual.

Desta forma o suporte e o local, interferindo na própria imagem, acabam por vincular a mensagem, espelhando-se como mais uma componente caracterizadora da obra, que assenta na relação técnica/tecnologia/local. Resultando de uma abordagem inerente à necessidade de interagirmos com a máquina, começa a aparecer uma aplicabilidade tecnológica que tem a capacidade de traduzir a natureza de forma tanto mais real quanto o real, procurando-se uma interação simbiótica/imersiva que possa simular a realidade, começando-se a formar o conceito de "realidade Virtual", que insere a ideia da participação total do corpo (não apenas a visão) em ambientes/situações geradas por computador que se tornem tão reais que possam ser recebidas como uma experiência real.

Temos então que mais do que traduzir realidades procura-se produzir realidades, ou seja, mais do que simulá-la procura-se substitui-la (VIRILIO, 1977). Nesta operação de "substituição" ganha força e passa a ser determinante a interação como elemento gerador de novas atitudes, quer por parte do autor quer por parte do observador, pois alteram-se as regras (que sempre foram usadas através da história da arte) para ambos os lados. A noção de autor passa a complementar o coletivo, e o observador passa a ser cativo. A imagem deixa de ser estática e passa a ser interativa - implicando uma ação física em ambos os sentidos.

Ora as imagens são sombras da realidade, como o coloca Platão na sua abordagem as imagens, que se fazem visíveis pelas semelhanças que projetam com o objeto que lhes deu origem, mas a semelhança é um lugar sem sentido no universo das realidades, uma vez que as imagens, sobretudo aquelas que nos tanto seduzem como induzem, estão balizadas pelos mecanismos que nos fazem vivenciar essa mesma realidade. A única condição de verdade que as imagens procuram ressalvar é a ilusão, mas através desta inscrevem a realidade no seu âmago. Pelo fato de estarmos constantemente expostos às imagens, inevitavelmente utilizamos, interpretamos e 
construímos significados para elas. Os aspectos simbólicos das imagens são convenções socioculturais, que não deixam dúvidas quanto à não universalidade de leitura da imagem, e quando se tende a ignorar esse lado (confundindo reconhecimento com significação) confundimos realmente percepção e interpretação. As imagens sempre foram e serão construções produzidas para evocar algo ausente, que pela sua função simbólica - que reside no significado - evidenciam um modo de ver pessoal, portanto não procuram replicar o mundo, sendo antes uma forma seletiva de o contar ${ }^{7}$.

O campo de ação em que se circunscreve a imagem define-se sobremaneira pela forma como está associada à visão, mas é pela intenção que ela se faz entrar no campo das artes plásticas. Pela sua relação com o fazer que se relacionava, no seu início, fortemente com a mão, essencialmente, antes do invento dos aparelhos que orbitam a sua produção, estava subentendida pela beleza. No entanto, com o desenvolvimento da sociedade, transformou-se num produto tão comercializado que acabou por ela própria ser adaptada. Com o advento da tecnologia é empurrada para o plano da simulação do mundo virtual. Contudo, as imagens são compostas por significados e como tal estão comprometidas por todas as imagens que lhes antecederam. Formam-se imagens a partir de imagens, portanto reinterpreta-se e assim dá-se origem a novas formas.

O próprio desejo é também provocado através das imagens e consequentemente afastam-se estas da realidade, o seu caráter consumista sobrepõe-se à própria imagem. Como estas são elementos preciosos numa sociedade consumista, tem a capacidade de fabricar fascínio - pelo fato, seduzem-nos tanto quanto nos prometem. Porém, é na representação que a imagem assume um valor simbólico, que se sobrepõe ao objeto e reforça a ilusão tornando a imagem em fetiche. Não obstante, constrói-se um referente simbólico, favorecendo e de algum modo continuando o primeiro patamar para a simulação, uma vez que a representação se encontra, ou produz, uma separação entre o mundo real e a sua imagem.

Temos portanto a imagem como um veículo de substituição, que se afirma e espelha naquilo que conhecemos, susceptível de criar ilusões, uma vez que a visão está sempre sujeita ao conhecimento perceptivo/cognitivo - compreende-se e deixa-se conhecer na aparência. É pela experiência que se conhece, pois articulando o interior (eu) e o exterior (meio) relacionam-se os sentidos e agregam-se as compreensões - que são parti- 
lhadas através da comunicações expostas por imagens entre o artista e o público - não dependendo apenas das características particulares do indivíduo ou da estrutura sócio-cultural em que se insere, mas do todo. A realidade é uma construção feita mediante e à medida de cada indivíduo. Portanto, é da responsabilidade de cada um o entendimento da realidade. Logo, nas imagens mais do que se tratar de correspondências é do modo como cada um a utiliza ${ }^{8}$. Assim, as imagens que temos mais presentes são, imperiosamente, aquelas que mais observamos (o museu imaginário), daí que o corpo de imagens que rodeia o seu fazedor seja determinante para perceber as imagens criadas. Acontece, através de um ciclo, uma ininterrupta dependência das imagens, fazendo com que incessantemente se desenvolvam mais imagens que sustentam e complexificam as nossas próprias memórias e imagens.

Obviamente que as imagens dependem de quem as observa e dependem da realidade que traduzem, que por sua vez está dependente do observador, mas em todas as realidades traduzidas procuram constituir espaços contemplativos (imersivos) com o objetivo de colocar o observador perante essa realidade apresentada, atribuindo dessa forma à imagem uma qualidade simulacral que em si compreende uma perda do senso da realidade.

Ao alterarmos a forma como percepcionamos o mundo, através da tecnologia digital, interferimos na função da própria arte. Organizando novos modelos de sensibilidade, tentando mudar consciências, obrigando os artistas a desafiarem as tecnologias e os métodos. Perde-se o caráter pessoal (autor) da obra pela intenção aleatória que esta requer do utilizador. A obra completa-se no observador/utilizador dando asas à sua subjetividade concluindo o seu desejo, enquanto imagem, na possibilidade de transferência.

Irremediavelmente, acredito eu, que a tecnologia interferiu na forma como vemos a realidade através das imagens provocando uma erosão no conceito de real. Passamos a ver mais coisas, a reconhecer o real através da sua simulação (BAUDRILLARD, 1992). Assim que se desenvolveu uma tecnologia capaz de extrapolar a imagem para longe do controle da mão desencadeou-se uma revolução com o meio e com a realidade. De uma forma totalitária a imagem concorre/avança para a consciência convertendo a própria realidade às suas necessidades. A tecnologia digital, por seu lado, provoca uma onipresença na imagem; não só transforma a realidade como proporciona novos paradigmas, levando à reformulação da 
própria realidade através de uma hibridação do inteligível e do visível, permitindo uma imersão poli-sensorial. É aqui que as imagens manipuladas digitalmente transportam na sua essência uma plasticidade tal que transforma a sua constatação, altamente imperceptível, em tarefa impossível, tornando a reprodução do real numa falência da credibilidade. Remetendo a imagem para longe do acampo das evidências, transforma-se em realidades que são em si modelos de representações mentais. Criou-se uma nova situação para a imagem, uma vez que tem a capacidade de desalojar/deslocar a realidade substituindo-a/recolocando-a. Pelo fato das imagens digitais serem números, o seu funcionamento reflete a sua estrutura - a imediatez. Na transformação operada entre a ação-reação, altera-se a noção do observador como elemento central e passa-se a operar com a consciência da autoria repartida, quer pela ação do sujeito físico - presença - ou pela ação do sujeito ausente - telepresença - no interior da obra. Na interface, pelo fato de ser o elemento que mediatiza a ação do homem com os computadores, refaz-se uma nova realidade, uma vez que a interface constrói o mundo que mediatiza por modelos, fazendo com que, perante os mundos da realidade virtual, o sujeito, a imagem e os objetos fiquem com propriedades idênticas e como tal não se possa falar em alinhamentos ou hierarquias. A tecnologia expõe o seu fim nos princípios para os quais é usada, o que implica dizer que a tecnologia têm sempre um objetivo preciso, colocando-a como tal oposta à criatividade. Portanto, tecnologia versus criatividade é um paradoxo.

Ou seja, ao disponibilizar todos os seus dados em todos os momentos, a tecnologia consente de forma tolerante à imagem uma adequação interativa na sua própria forma de ser, convertendo-a num sistema dinâmico que absorve/arrasta com ela o observador. Converte-se a imagem tida como "janela" em "passagem", ao permitir-se não apenas a sua observação/contemplação, mas participando-se democraticamente na sua criação e alteração/reconversão. Pelo desempenho da tecnologia, espaço e imagem reagem à presença do indivíduo produzindo ciclos de continuidades que se espelham na instalação interativa. Se a representação, pela sua ligação com a ilusão, foi um dos garantes da imagem até ao início do século $\mathrm{XX}$, com a tecnologia digital acentua-se a sua interseção com a simulação, pela sua capacidade de gerar objetos "reais" sem necessidade dos objetos (perda de referente), condicionamos a realidade à sua simulação, e a tradução do real pelo imaginário, 
garante da ilusão, entra em crise, na medida em que, a simulação apela ao real, criando "falsos reais". As imagens digitais, na sua essência, não procuram uma aproximação ao real, são uma outra realidade, não se trata de provar que é real, mas de aceitar a sua autonomia. Outro fator que interfere nos julgamentos morais associados à tecnologia, prendem-se com o fato do direito autoral perder paternidade singular, que assegurava a genuinidade e complementava a verdade representada, dissolvendo os conceitos de originalidade. Na transformação operada pela interatividade (passivo vs ativo), compreende-se um problema: é uma relação dependente/disponível de dois quereres e se algum dos lados "falhar" (tecnologicamente ou pelo desinteresse) nada acontece e produto multi/pluri/inter, não se concretiza, daí a importância do princípio da convergência.

Não nos podemos esquecer que todas as formas de expressão artísticas e desde sempre vincularam uma interação, mas a partir dos meados do século XX essa interação transforma-se, acentuando e implicando mais do que a fruição a participação mental do espectador, o que vai interferir implicitamente na estrutura do mundo da arte. Nivela-se a obra, o autor e o observador, inferindo-se sobre o observador pela ação participativa esperada na obra, converte-se o observador/passivo em utilizador/ ativo.

Ao conceber-se a imagem para colher a participação está-se também a alterar o indivíduo que lá vai participar, pois pelo fato de ser permitido colocar cada utilizador a transformar a obra, que passa a incluir o indivíduo como um elemento constituinte, afirma-se a consciência do coletivo, que ao mesmo tempo requalifica o objeto tornando-o pluri-multi-disciplinar.

Nesta condição física, para que se constituía interação são necessários três fatores, que se agregam e dissolvem na obra, ou seja, simulação, participação e concretização em tempo real. Nesta junção desmaterializa-se o objeto e a própria figura do criador que ao procurar/permitir a interatividade está ele mesmo a ser manipulado/condicionado pela tecnologia que vai interferir em todo o seu processo de reflexão acerca da obra final, que não se concretiza enquanto objeto mas e apenas se torna em espaços de possibilidades, nem público nem produtor tem capacidade para concluir a obra que se encontra sempre aberta (ECO, 1989).

De outra forma, pela constatação da palavra "virtual", remete-se o significado da realidade que se pretende abordar para a simulação/mutação/ilusão que se adequa perfeitamente ao eu e à arte. Ao opor-se ao atual/concreto o vir- 
tual orienta uma certa subjetividade na imagem de que se constitui, transformando estas em verdadeiras construtoras de significado, interferindo esteticamente com o objeto, proporcionando a passagem de uma sociedade de cultura objetual, da estabilidade da informação, para uma sociedade da cultura do fluxo, da instabilidade da informação. Pelo fato da tecnologia nos permitir imergir e interagir com a imagem, o que orienta uma certa lógica criativa da estética tecnológica, é sintomático e reflete a integração/dependência do produtor/obra/utilizador da e para com a tecnologia, o que torna o conceito da interatividade num dos aspectos mais estimulantes para o campo da criatividade.

Uma boa forma de desconstruir a ideia de criatividade encontra-se no ato de converter a regularidade em irregularidade, na medida em que procura oferecer uma alternativa original que se desenha, quando intencional, entre a inspiração e a reflexão, o que nos leva a designar a criatividade como um ato de transformação ou modificação a cargo das convenções em que está inserido. O que nos permite, por outro lado, perceber que a criatividade não consiste necessariamente na produção de algo "novo", mas num processo capaz de gerar um conjunto de possibilidades definido por um grupo de requisições e de restrições.

Através das várias formas de interação participativa assenta na convergência de interesses, criam-se condições para se desenvolverem novos espaços, novos territórios, para o utilizador (observador convertido em utilizador, mutação derivada da atitude passiva vs ativa) proporcionando o estado de work-in-progress, colocando como questão central e apetecível o credo absoluto da interatividade, remetendo o ato da criação mais para o campo da seleção do que o de uma procura do "novo", mais do que criar vemos aparecer a obra pela ação de juntar, reforçando a ideia que o sentido da criação está a ser substituído pelo da seleção, acrescido pela tecnologia, colocando-nos perante uma transformação da atitude criadora em atitude modificadora.

\section{Referências Bibliográficas}

BAUDRILLARD, Jean. A Sociedade de Consumo. Col. Espaço da Sociologia. Lisboa: Edições 70, 1981.

The Precession of Simulacra. in WALLIS,

Brian (ed). Art After Modenism: Rethinking Representation, 
6a ed. Nova Iorque: The New Museum of Contemporary Art, 1992, p.253-282.

Londres: SAGE, 1997. Art and Artefact. ZURBRUGG, Nicholas (ed.). .O Sistema dos Objectos. Col. Debates ํㅜ.70. São Paulo: Ed. Perspectiva, 1997. .De la Seduccion. Madrid: col. Teorema, serie mayor. 8a edição. Edições Cátedra, 2000.

BENJAMIN, Walter. A Obra de Arte na Era da sua Reprodutibilidade Técnica. In: Sobre Arte, Técnica, Linguagem e Política. Col. Antropos. Lisboa: Relógio D’Água, 1992. p.71-113.

ECO, Umberto. Obra Aberta. Lisboa: Difel, 1989.

FOULCAULT, Michel. What Is an Author?. In HARARI, Josue V. Textual Strategies: Perspectives In Post-Structuralist Criticism. Londres: Methuen, 1979, p.141-16o.

GASSET, José Ortega y. A Desumanização da Arte. São Paulo: Cortez Editora, 1991.

GILLES, Deleuze. Cinema 1: the Movement-Image, Londres: The Athlone Press, 1986. Athlone Press, 1989.

Cinema 2: the Time-Image. Londres: The

GOMBRICH,Ernst H. The Image and the Eye: Further Studies in the Psychology of Pictorial Representation. Londres: Phaidon, 1994 . . The Story of Art. Londres: Phaidon, 1995.

GRAU, Oliver. Virtual Art: From Illusion to Immersion. Cambridge: MIT Press, 2003.

HUYGHE, René. O Poder da Imagem. Col. Arte \& Comunicação, no.29. Lisboa: Edições 70, 1998.

JOLY, Martine. Introdução à Análise da Imagem. Col. Ofício de Arte e Forma. São Paulo: Papirus, 1996.

KRAUSS, Rosalind. The Originality of the Avant-Garde: A Postmodern Repetition. In WALLIS, Brian e TUCKER, Marcia (ed). Art After Modenism: Rethinking Representation, 6 ed. Nova Iorque: The New Museum of Contemporary Art, 1992, p.13-30.

. A Note on Photography and the Simulacral. In Winter Squiers. CAROL (ed.). Over Exposed: Essays on Contemporary Photography. Nova Iorque: New Press, 1999, p.169-182.

MACHADO, Arlindo. Pré-cinema E Pós-Cinema. São Paulo: Papirus Editora, 1997.

. Repensando Flusser e as Imagens Técnicas. 
In Real vs. Virtual. Revista de Comunicação e Linguagens, no 25/26, Lisboa: Edições Cosmos, 1999, p.31-46.

MCLUHAN, Marshall. Understanding Media: the Extensions of Man. Col. A Mentor Book. Nova Iorque: The New American Library, 1964.

SONTAG, Susan. Ensaios sobre Fotografia. Col. Arte e sociedade, n‥5. Lisboa: Publicações Dom Quixote, 1986. VIRILIO, Paul. Vitesse et Politique Paris: Galilée, 1977

\section{NOTAS}

1. Realidade essa que era tida e vista como o "visível" e para tal usaram, inclusive, os aparelhos derivados da investigação da época, nomeadamente a "câmara obscura" com o propósito de traduzir a natureza do modo mais objetivo possível - as imagens obtidas eram, obviamente, a própria realidade que se fazia projetar na parede oposta ao orifício por onde penetrava a luz e assim o artista registava o visível e não a imaginação.

2. Pela apropriação da técnica, enquanto processo vinculador do conhecimento, o artista começa a afastar-se do artesão. Com o objetivo de ser bem acolhido no seio da sociedade do seu tempo, procura, mais do que usar a habilidade, usar o intelecto na construção do espaço da representação.

3. Através da desmultiplicação dos livros que passam a ser reproduzidos mecanicamente a imagem começa a percorrer distâncias inimagináveis para a própria pintura, tendo como tal que se confrontar com a sua verosimilhança, enquanto representação, do representado com o real, obrigando a sua execução a ser tanto mais precisa quanto inquestionável.

4. Desenvolve-se a critica e as academias com programa, porém ainda longe de terem ensinamentos sistematizados, começam a florescer pela Europa passando a substituir as corporações de artes e ofícios - pela mão da liberalização do conhecimento proporcionada pela academia, a produção de imagens começam a estar ao alcance de classes menos favorecidas e assim o número de indivíduos interessados em produzir aumentou significativamente.

5. O que por sua vez acaba por fazer realçar o problema da arte como sendo um problema de forma. Forma que traduz o modo de ver e experimentar a realidade do indivíduo artista, colocando a visão no centro da produção da obra.

6. Para representar de forma fotográfica o objeto deixamos de ter o objeto ele mesmo - criamos uma realidade que não necessita da realidade para ser traduzida.

7. A semiologia procura formar uma produção de sentido para se interpretar as imagens, procura perceber o modo como estas fomentam significações fazendo com que, na qualidade de signos, tenham que exprimir ideias e como tal incitar no observador uma atitude interpretativa. $O$ signo não atua de forma indiferente ao meio e para que este se constitua são necessários outros signos simultâneos para lhe dar sentido, para o signo significar temos que o colocar num contexto.

8. A construção significativa da imagem (aquilo que uma coisa exprime ou representa) pressupõe uma interação entre o que conhecemos e o que queremos conhecer, gerando uma expectativa.

Recebido em: 24/10/2010

Aceito em: 14/02/2011 


\section{PAULO BERNARDINO \\ pbernard@ua.pt}

Paulo Bernardino, nasceu na cidade do Porto em 1963, é Doutor (PhD) em Estudos de Arte e Professor (diretor) do programa de pós-graduação em Criação Artística Contemporânea na Universidade de Aveiro.

Enquanto Artista começa por utilizar, como meio de expressão, técnicas mais tradicionais enquadradas pelas disciplinas do desenho e da escultura, estando atualmente direcionado para os meios de produção tecnológicos, através da imagem, procura intersectar, na sua obra, a tecnologia digital como ponto de fusão. 